\title{
Foreseeable evolution in sclerotherapy
}

\author{
GM Malouf ${ }^{1}$ \\ ${ }^{1}$ Private practice, Sydney Australia
}

submitted: Aug 25, 2020, accepted: Aug 25, 2020, EPub Ahead of Print: Aug 25, 2020, published: Aug 25, 2020

Conflict of interest: None

DOI: 10.24019/jtavr.86 - Corresponding author:Dr. G Mark Malouf, surgeon@ varicoseveins.com.au>

(C) 2018 Fondazione Vasculab impresa sociale ONLUS. All rights reserved.

Sclerotherapy is performed in virtually every phlebology practice daily. It is a pillar of current varicose veins management. Practising phlebology without sclerotherapy is like using a table with one leg missing! Sclerotherapy is a safe and effective treatment method of chemically ablating troublesome refluxing superficial leg veins, and also unwanted cutaneous reticular and spider veins and to treat venous malformations. Liquid or foamed sclerosants cause destruction of the endothelial vein lining, with possibly damage also to the media, producing vein spasm, fibrosis and eventual sclerosis. I prefer to think of it as more of an art form than a science, and heavily dependent on the patient's response to what is injected.

Sclerotherapy attempts were first reported around 1682 by Zollikofer in Switzerland. The technique failed to gain acceptance due to morbid complications. It remained practically abandoned until less damaging and more effective sclerosants were discovered in the early 1920s. Improved methods of delivering effective and safe sclerosants now exist. Regular attempts have been made to improve the efficacy and safety profile of sclerotherapy.

For example the addition of graduated compression following sclerotherapy, the widespread trend to foam detergent sclerosants before injection, the use of duplex ultrasound to accurately place needles and cannula/ catheters for better sclerosant delivery, upper limits placed on the volume of sclerosants administered - many guidelines available, the placement of tumescent fluid around veins treated by sclerotherapy and the use of special infrared vein imaging technology, are currently in use. In this issue of the journal you will read from Fattahi his suggested improvement, termed Foam Washout Sclerotherapy.
Sclerotherapy can be used as a single treatment method for all varicose veins ${ }^{1}$ or can be used in combination with thermal ablation of saphenous trunks, tributaries and extensions, or following cyanoacrylate glue treatment to trunks and also combined with surgical removal of saphenous trunks and prominent tributary varicosities. Conservative venous surgery can also benefit from associated sclerotherapy.

PRO studies comparing the results of varicose veins treatments report comparable improvement in Quality of Life (QoL) following sclerotherapy to the other popular treatment methods. This, combined with the lower cost structure of sclerotherapy, has lead many to push it up the list of recommended varicose veins treatment options ${ }^{2}$. Newly developing vein treatment methods such as high intensity focussed ultrasound (HIFU) may benefit from additional sclerotherapy. Variable combinations of these treatment methods depend on the exact venous pathology, the training and experience of the treating doctor, the equipment available and the financial cost to be incurred.

Sclerotherapy will always remain in the phlebology tool box, mostly being used in an "a-la-carte" fashion to complement other treatments. Current sclerosants, which include detergents, hyperosmolar and corrosive agents, are relatively safe and effective. Adequate performance of sclerotherapy for both large and small veins requires training, experience and skill. It is extremely "operator dependent" and the occasional poor results from sclerotherapy are often the result of poorly performed sclerotherapy.

How will sclerotherapy evolve in the future? I see evolution coming in proper training of doctors in sclerotherapy, in further studies on the many effects of 
foam sclerosants and associated gases used to make them and in suitable interaction between sclerotherapy and new emerging vein treatments like HIFU. I hope an increasing availability of ultrasound in all countries will allow better placement of sclerosants, improving sclerotherapy results. I see a major rise in the aesthetic use of sclerotherapy. Demands for improvement in appearance are on the increase with rising affluence. Commercial distribution of sclerosants is increasingly via aesthetic companies. The numbers of doctors interested in entering this field is growing. Microsclerotherapy combined with transdermal laser vein treatment, aided by infrared vein illumination is growing in popularity.

The hunger among doctors to learn good sclerotherapy skills to treat large and small veins is increasing. More available theoretical and hands-on

\section{References}

1) Lawaetz M, Serup J, Lawaetz B, Bjoern L, Blemings A, Eklof B, Rasmussen L. Comparison of endovenous ablation techniques, foam sclerotherapy and surgical stripping for great saphenous varicose veins. Extended 5-year follow-up of a RCT. International Angiology 2017 June;36(3):281-8. Available from: https://doi.org/10.23736/S0392-9590.17.03827-5 training, and certification, provided by phlebology craft groups and sclerosant manufacturers must be part of the evolution

After many years in phlebology practice, most of us have large numbers of old patients requiring maintenance therapy. We sometimes fear that old patients may dominate the new patient numbers. Sclerotherapy will always be of use in this space for effective and inexpensive treatment of the new veins encountered - often tortuous thin walled refluxing non-anatomical neo-veins. These patients can expect such recurrences over time, and during their followup visits they can expect regular sclerotherapy, probably using ultrasound guided foam. Whatever new venous treatments arise, they will have to be accompanied by well performed sclerotherapy.

2) Davies HO, Popplewell M, Darvall K, Bate G, Bradbury AW. A review of randomised controlled trials comparing ultrasound-guided foam sclerotherapy with endothermal ablation for the treatment of great saphenous varicose veins. Phlebology: The Journal of Venous Disease $2015 \mathrm{Jul}$ 9;31(4):234-40. Available from: https://doi.org/10.1177/0268355515595194 